\title{
Monte Carlo Valuation of Natural Gas Investments
}

\author{
Luis M. Abadie \\ Bilbao Bizkaia Kutxa \\ Gran Vía, 30 \\ 48009 Bilbao, Spain \\ Tel +34-607408748 \\ Fax +34-944017996 \\ E-mail: imabadie@euskalnet.net \\ José M. Chamorro \\ University of the Basque Country \\ Dpt. Foundations of Economic Analysis I \\ Av. Lehendakari Aguirre, 83 \\ 48015 Bilbao, Spain \\ Tel. +34-946013769 \\ Fax +34-946013891 \\ E-mail: jm.chamorro@ehu.es
}

This draft: February 22, 2006

\begin{abstract}
This paper deals with the valuation of energy assets related to natural gas. In particular, we evaluate a baseload Natural Gas Combined Cycle (NGCC) power plant and an ancillary instalation, namely a Liquefied Natural Gas (LNG) facility, in a realistic setting; specifically, these investments enjoy a long useful life but require some non-negligible time to build. Then we focus on the valuation of several investment options again in a realistic setting. These include the option to invest in the power plant when there is uncertainty concerning the initial outlay, or the option's time to maturity, or the cost of $\mathrm{CO}_{2}$ emission permits, or when there is a chance to double the plant size in the future.

Our model comprises three sources of risk. We consider uncertain gas prices with regard to both the current level and the long-run equilibrium level; the current electricity price is also uncertain. They all are assumed to show mean reversion.

The two-factor model for natural gas price is calibrated using data from NYMEX NG futures contracts. Also, we calibrate the one-factor model for
\end{abstract}


electricity price using data from the Spanish wholesale electricity market. Then we use the estimated parameter values alongside actual physical parameters from a case study to value natural gas plants.

Finally, the calibrated parameters are also used in a Monte Carlo simulation framework to evaluate several American-type options to invest in these energy assets. We accomplish this by following the least squares $\mathrm{MC}$ approach.

Keywords: Real options, power plants, stochastic revenues and costs, $\mathrm{CO}_{2}$ allowances, $\mathrm{LNG}$

Acknowledgement 1 We thank James Oliver and Scott Byrne, of NYMEX (London), for providing us with the data on natural gas futures contracts.

\section{Introduction}

Energy resource prices in general are now at or near record levels. This situation may be explained both from the demand side and the supply side. With regard to the former, strong economic growth in America, on the one hand, and in China and India, on the other, has placed world reserves under substantial pressure. At the same time, new discoveries and investment by the industry have not kept pace. In sum, energy markets are currently very tight, and energy security concerns sound ever louder. As a consequence, consumers can arguably expect any external shock to translate into greater volatility of oil and gas prices.

In the case of energy investments, this uncertain environment is coupled with irreversibility considerations, or a chance to defer investment, or to manage it in a flexible way. Under these circumstances, valuation techniques based on the methods for pricing options (such as Contingent Claims Analysis or Dynamic Programming) are superior to traditional approaches based on discounted cash flows. In addition, power utilities (at least in the European Union) now face a new carbon market which, regardless of whether it is seen as a threat or an opportunity, no doubt will influence decision making.

The aim of this paper is to use the real options methodology to evaluate energy investments related to natural gas, which is gaining market share to the detriment of crude oil, let alone standard coal. In particular, we evaluate a baseload Natural Gas Combined Cycle (NGCC) power plant and an ancillary facility, namely a Liquefied Natural Gas (LNG) facility, in a realistic setting; specifically, these investments enjoy a long useful life but require some nonnegligible time to build. ${ }^{1}$ Then we focus on the valuation of several investment options again in a realistic setting. These include the option to invest in the power plant when there is uncertainty concerning the initial outlay, or the option's time to maturity, or the cost of $\mathrm{CO}_{2}$ emission permits, or when there is a chance to double the plant size in the future. ${ }^{2}$

Our model comprises three sources of risk. We consider uncertain gas prices with regard to both the current level and the long-run equilibrium level; the

\footnotetext{
${ }^{1}$ Majd and Pindyck [17] analyze this subject, which is typically neglected.

${ }^{2}$ See Trigeorgis [27] for an intuitive exposition of this and related options.
} 
current electricity price is also uncertain. They all are assumed to show mean reversion. Specifically, they are assumed to follow an Inhomogeneous Geometric Brownian Motion (IGBM). This is a more general stochastic process in that it reduces to standard Geometric Brownian Motion, or even accounts for jumps in the state variable, depending on its parameter values.

The two-factor model for natural gas price is calibrated using data from NYMEX NG futures contracts. The specific procedure is based on Cortazar and Schwarz [8]. Also, we calibrate the one-factor model for electricity price with data from the Spanish wholesale electricity market. Then we use the estimated parameter values alongside actual physical parameters from our case study to value natural gas plants.

Finally, the calibrated parameters are also used in a Monte Carlo simulation framework to evaluate several American-type options to invest in these energy assets. ${ }^{3}$ We accomplish this by following the Least Squares Monte Carlo (LSM) approach as developed by Longstaff and Schwarz [15].

The paper is organized as follows. Section 2 briefly describes the technology for producing electricity in a gas-fired power plant. Then we introduce that for storing natural gas; it has the potential to connect previously fragmented markets by unlocking the intimate relation between consumers and local providers. Section 3 shows the mean-reverting stochastic process for input and output prices. For valuation purposes, the risk-neutral version of the model is then derived. Also, since we adopt Monte Carlo simulation below as a numerical technique, the model must be adapted to a discrete-time context. Section 4 aims to get the parameter values of the stochastic processes. To this end, the model for the gas price and that for electricity are separately calibrated using actual data. Section 5 describes our case study; it includes physical parameter values of the NGCC plant and the LNG plant. In Section 6 we derive the value of each plant in operation. Then Section 7 evaluates several options to invest in a NGCC power plant. A section with final remarks concludes.

\section{Basic description}

\subsection{The NGCC technology}

It is based on the employment of two turbines, one of natural gas and another one of steam. The exhaust gases from the first one are used to generate the steam that is used in the second turbine which produces approximately one-third of the total power output. Thus it consists of a Gas-Air (Brayton) cycle and a Water-Steam (Rankine) cycle. This system allows for a higher net efficiency than coal-fired power plants, ${ }^{4}$ close to $55 \%$; future trends aim at reaching net efficiencies of $60 \%$ in NGCC plants of $500 \mathrm{Mw}^{5}$

\footnotetext{
${ }^{3}$ See, among others, Cortzar and Schwartz [7].

${ }^{4}$ The net efficiency refers to the percentage of the heating value of the fuel that is transformed into electric energy.

${ }^{5}$ See Watson $[28]$.
} 
The advantages of a NGCC power plant are: ${ }^{6}$

a) Lower emissions of $\mathrm{CO}_{2}$, estimated about $350 \mathrm{~g} / \mathrm{Kwh}$, which allow an easier fulfillment of the Kyoto protocol;

b) Higher net efficiency, between $50 \%$ and $60 \%$;

c) Low cost of the investment, about $422.5 € / \mathrm{Kw}$ installed;

d) Less consumption of water and space requirements, which allow to build in a shorter period of time and closer to consumer sites. A NGCC power plant can be built in 30 months $^{7}$ employing $100 \mathrm{~m}^{2} / M W$.

e) Useful life of 25 years.

f) Lower operation costs, with typical values of 0.35 cents $€ / \mathrm{KWh}$.

g) Depending on the design of the gas turbine, some facilities can use other combustibles as gas oil and fuel.

In addition, a NGCC power plant can be designed as a baseload plant or as a peaking plant; in the latter case, it only operates when electricity prices are high enough, what usually happens during periods of strong growth in demand.

The advantages of the NGCC Power Plants make it easier to obtain permissions of construction by new electricity producers.

On the other hand, the disadvantages of a NGCC Power Plant are:

a) The higher cost of the natural gas fired in relation to coal's;

b) The insecurity concerning gas supplies, since reserves are more unevenly distributed over the world;

c) The strong rise in the demand for natural gas, which can cause a consolidation of prices at higher than historical levels. Nonetheless, the spreading of Liquefied Natural Gas (LNG) plants entails an improvement in ensuring fuel supplies and a stronger link among formerly geographically fragmented natural gas markets.

\subsection{The LNG technology}

A Liquefied Natural Gas (LNG) plant stores liquefied gas in cryogenic tanks after being downloaded from the vessels in which it is transported at a temperature of $-160^{\circ} \mathrm{C}$. Then it is regasified and pumped into the gas pipelines so as to make it avaliable for the consuming units, for instance a NGCC power plant. The liquefied gas comes from liquefying plants located at the producing countries. Thus a power utility in a developed country may purchase and import gas from distant producers at affordable prices; this may be sensible not only on economic grounds, but on diversification and reliability concerns as well.

A LNG plant can be modelled as a spread option between using domestic gas or buying foreign gas, at any time choosing the cheapest possibility while increasing supply reliability. A restrictive requirement for the construction of one of these facilities is the need of a coastal site with a sufficiently deep port to harbour LNG freight vessels.

\footnotetext{
${ }^{6}$ Our reference is ELCOGAS [10]: "Integrated gasification combined cycle technology: IGCC" and its actual application at the power plant in Puertollano (Spain).

${ }^{7}$ In some cases the time of construction has dropped to a year. See Watson[28].
} 
To the extent that these plants allow for access to new natural gas markets, their construction enables these markets to get interlinked, depending on the arbitrage opportunities once transport costs between different sites have duly been accounted for.

\section{The stochastic model for input and output prices}

The stochastic behaviour of energy prices shows both a short-term and a longterm dynamics. ${ }^{8}$ The short run behaviour displays mean reversion, seasonality, stochastic volatility and, in some instances, discrete jumps; long run behaviour, though, is determined by equilibrium price's dynamics. Since one aim of the paper is to value an asset (a baseload NGCC plant) with 25 years of useful life, seasonality and jumps have been deemed less relevant. ${ }^{9}$

\subsection{A three-factor model}

The following model is adopted:

$$
\begin{gathered}
d G_{t}=k_{g}\left(L_{t}-G_{t}\right) d t+\sigma_{g} G_{t} d W_{t}^{G}, \\
d L_{t}=\mu\left(L_{g}-L_{t}\right) d t+\xi L_{t} d W_{t}^{L}, \\
d E_{t}=k_{e}\left(L_{e}-E_{t}\right) d t+\sigma_{e} E_{t} d W_{t}^{E},
\end{gathered}
$$

where:

$G_{t}$ : the price of natural gas at time t.

$L_{t}$ : the natural gas equilibrium price level, which behaves according to equation (2).

$k_{g}$ : the speed of reversion of natural gas price towards its "normal" level. It can be computed as $k_{g}=\log 2 / t_{1 / 2}$, where $t_{1 / 2}$ is the expected half-life, that is, the time for the gap between $G_{t}$ and $L_{t}$ to halve.

$\sigma_{g}$ : the instantaneos volatility of fuel price. $L_{g}$.

$\mu$ : the speed of reversion of $L_{t}$ towards its longer-term equilibrium value

$\xi$ : the instantaneos volatility of natural gas equilibrium price.

\footnotetext{
${ }^{8}$ Schwartz and Smith [24] discuss these twin dynamics in a model which allows for mean reversion in the short term and uncertainty in the equilibrium price to which prices revert. See also Pilipovic [19] and Baker, Mayfield and Parsons [1].

${ }^{9}$ Seasonality would be much more important in a valuation model for the short run. It could be included by means of a function $f(t)$ in the expression for the current price $G_{t}$. In this case, the formulae in this paper would correspond to the deseasonalised series. Concerning price jumps, in case there are, they would only be important to the extent that they have an impact on average prices; thus they should be taken into account when computing the parameters of the stochastic model adopted.
} 
$E_{t}$ : the price of electricity at time t.

$k_{e}$ : the speed of reversion of electricity price towards its "normal" level in the long run $L_{e}$.

$\sigma_{e}$ : the instantaneos volatility of electricity price.

$d W_{t}^{G}, d W_{t}^{L}$ and $d W_{t}^{E}$ : increments to a standard Wiener process. They are assumed to be normally distributed with mean zero and variance $d t$. It is further assumed that $\rho_{W^{G} W^{L}}=\rho_{W^{L} W^{E}}=0$ and $\rho_{W^{G} W^{E}}=\rho .^{10}$

This model has some convenient implications:

a) There is no chance for $G_{t}$ or $E_{t}$ to take on negative values.

b) It allows the existence of an equilibrium level for both natural gas and electricity output. In the former's case, the equlibrium price is not constant.

c) Expected values of long-run equilibrium prices remain finite, $L_{g}$ and $L_{e} \cdot{ }^{11}$

d) The stochastic process for natural gas price is similar to Pilipovic [19] model; yet they differ in that equation (2) above is of the IGBM type, as opposed to the standard GBM in Pilipovic. ${ }^{12}$ This kind of models looks preferable if the equilibrium price in the longer term is determined by production cost and demand level.

e) The model allows for price jumps depending on parameter values.

f) It also allows, as a particular case, that equations (1) and (2) adopt a GBM format, again depending on the values of the parameters.

g) Consistent with furures markets, volatilities do not grow without bound as $t \rightarrow \infty$; instead, they approach a finite value if reversion speed is high enough in relation to volatility.

The expected value of natural gas price is (equation (57) in the Appendix):

$$
E\left(G_{t}\right)=L_{g}-\frac{k_{g}\left(L_{0}-L_{g}\right)}{\mu-k_{g}} e^{-\mu t}+\left[G_{0}-L_{g}+\frac{k_{g}\left(L_{0}-L_{g}\right)}{\mu-k_{g}}\right] e^{-k_{g} t} .
$$

For $L_{g}=0$ and $\mu=-\varphi$ equation (2) reduces to:

$$
d L_{t}=\varphi L_{t} d t+\xi L_{t} d W_{t}^{L} .
$$

In this case, the expected value becomes:

$$
E\left(G_{t}\right)=\frac{k_{g} L_{0}}{\varphi+k_{g}} e^{\varphi t}+\left[G_{0}-\frac{k_{g} L_{0}}{\varphi+k_{g}}\right] e^{-k_{g} t} .
$$

On the other hand, the expected value of electricity price is:

$$
E\left(E_{t}\right)=L_{e}+\left(E_{0}-L_{e}\right) e^{-k_{e} t}
$$

\footnotetext{
${ }^{10}$ Similarly to Pilipovic model [19] for $\rho_{W^{G} W^{L}}=0$.

${ }^{11}$ In this model $E\left(L_{t}\right)=L_{g}+\left(L_{0}-L_{g}\right) e^{-\mu t}$, which implies $E\left(L_{\infty}\right)=L_{g}$.

${ }^{12}$ In Pilipovic's model there is no equilibrium price in the long run unless the trend is zero.
} 


\subsection{The risk-neutral model}

The model in a risk-neutral world would be:

$$
\begin{gathered}
d \hat{G}_{t}=\left[k_{g}\left(\hat{L}_{t}-\hat{G}_{t}\right)-\lambda_{g} \sigma_{g} \hat{G}_{t}\right] d t+\sigma_{g} \hat{G}_{t} d W_{t}^{G}, \\
d \hat{L}_{t}=\left[\mu\left(L_{g}-\hat{L}_{t}\right)-\lambda_{l} \xi \hat{L}_{t}\right] d t+\xi \hat{L}_{t} d W_{t}^{L}, \\
d \hat{E}_{t}=\left[k_{e}\left(L_{e}-\hat{E}_{t}\right)-\lambda_{e} \sigma_{e} \hat{E}_{t}\right] d t+\sigma_{e} \hat{E}_{t} d W_{t}^{E},
\end{gathered}
$$

where:

$\lambda_{g}:$ is the market price of risk stemming from current natural gas price (assumed to be constant).

$\lambda_{l}$ : is the market price of equilibrium gas price risk.

$\lambda_{e}$ : is the market price of current electricity price risk.

In this risk-neutral setting, the expected value of natural gas price, as shown by equation (58) in the Appendix, is:

$$
\begin{aligned}
E\left(\hat{G}_{t}\right)= & \frac{\mu k_{g} L_{g}}{\left(\mu+\lambda_{l} \xi\right)\left(k_{g}+\lambda_{g} \sigma_{g}\right)}\left(1-e^{-\left(k_{g}+\lambda_{g} \sigma_{g}\right) t}\right)+ \\
& +\left[\frac{\mu k_{g} L_{g}}{\left(\mu+\lambda_{l} \xi\right)\left(\mu+\lambda_{l} \xi-k_{g}-\lambda_{g} \sigma_{g}\right)}-\frac{k_{g} L_{0}}{\left(\mu+\lambda_{l} \xi-k_{g}-\lambda_{g} \sigma_{g}\right)}\right] . \\
& \cdot\left(e^{-\left(\mu+\lambda_{l} \xi\right) t}-e^{-\left(k_{g}+\lambda_{g} \sigma_{g}\right) t}\right)+G_{0} e^{-\left(k_{g}+\lambda_{g} \sigma_{g}\right) t}
\end{aligned}
$$

This value $E\left(\hat{G}_{t}\right)$ equals the estimated futures price of natural gas $\hat{F}_{t}$ for maturity $t$.

For an arbitrarily long maturity, the estimate for the futures price would be:

$$
\hat{F}_{\infty}=\frac{\mu k_{g} L_{g}}{\left(\mu+\lambda_{l} \xi\right)\left(k_{g}+\lambda_{g} \sigma_{g}\right)} .
$$

Now the expression for the forward risk premium would be the difference between the values in equations (4) and (11):

$$
R P_{g_{t}}=E\left(G_{t}\right)-E\left(\hat{G}_{t}\right) .
$$

If $L_{g}=0$ and $\mu=-\varphi$ the equation reduces to:

$$
E\left(\hat{G}_{t}\right)=G_{0} e^{-\left(k_{g}+\lambda_{g} \sigma_{g}\right) t}+\frac{k_{g} L_{0}}{\left(\varphi-\lambda_{l} \xi+k_{g}+\lambda_{g} \sigma_{g}\right)}\left(e^{\left(\varphi-\lambda_{l} \xi\right) t}-e^{-\left(k_{g}+\lambda_{g} \sigma_{g}\right) t}\right) .
$$

The risk neutral version for the electricity price is:

$$
E\left(\hat{E}_{t}\right)=E_{0} e^{-\left(k_{e}+\lambda_{e} \sigma_{e}\right) t}+\frac{k_{e} L_{e}}{\left(k_{e}+\lambda_{e} \sigma_{e}\right)}\left(1-e^{-\left(k_{g}+\lambda_{e} \sigma_{e}\right) t}\right) .
$$




\subsection{The discrete-time version}

In our Monte Carlo simulations below, we shall use the following discretization of equations (8), (9) and (10):

$$
\begin{gathered}
\Delta \hat{G}_{t}=\left[k_{g} \hat{L}_{t}-\hat{G}_{t}\left(k_{g}+\lambda_{g} \sigma_{g}\right)\right] \Delta t+\hat{G}_{t} \sigma_{g} \sqrt{\Delta t} \epsilon_{t}^{G}, \\
\Delta \hat{L}_{t}=\left[\mu L E-\hat{L}_{t}\left(\mu+\lambda_{l} \xi\right)\right] \Delta t+\hat{L}_{t} \xi \sqrt{\Delta t} \epsilon_{t}^{L}, \\
\Delta \hat{E}_{t}=k_{e}\left(L_{e}-\hat{E}_{t}\right) \Delta t+\sigma_{e} \hat{E}_{t} \sqrt{\Delta t} \epsilon_{t}^{E},
\end{gathered}
$$

where $\epsilon_{t}^{G}, \epsilon_{t}^{L}$ and $\epsilon_{t}^{E}$ are standard Normal variates and $\Delta t$ is measured in yearly terms. Whereas $\epsilon_{t}^{G}$ and $\epsilon_{t}^{L}$ are assumed to be independent, and also $\epsilon_{t}^{L}$ and $\epsilon_{t}^{E}$, so $\rho_{G, L}=\rho_{L, E}=0.0$, the correlation coefficient between electricity and natural gas prices $\rho_{G, E}$ may be different from zero. Note that since there is no futures electricity market from which to infer a risk premium, we assume $\lambda_{e}=0$.

\section{Parameters of the stochastic processes}

\subsection{Calibrated model for natural gas price}

Our data set consists of NYMEX NG futures prices from January 5th 2004 to April 29th 2005, a total of 330 days. This series has been deseasonalised for later use in all our computations. ${ }^{13}$ It is assumed that seasonality has a rather limited impact on investment valuations when long time horizons (e.g. 25 years) are involved. ${ }^{14}$ Figure 1 shows futures prices on a typical day and also the deseasonalised series on that day. The seasonal component displays a strong regularity. ${ }^{15}$

Figure 2 shows deseasonalised prices for futures contracts with one month and five years to maturity. As in some related papers, it can be noted that volatility decreases as the time horizon increases. ${ }^{16}$ On the other hand, the positive drift observed in futures prices along trading sessions seems to suggest a structural change in the market, e.g. in the form of a higher equilibrium price level.

Now we describe the calibration procedure. It is based on the approach developed by Cortazar and Schwartz [8], who propose a method which minimizes a sum of squared errors. These errors are the difference between actual furures prices and those computed at each time as a function of global parameters and

\footnotetext{
${ }^{13}$ This has been acomplished by using the Arima-X12 procedure.

${ }^{14}$ At the moment of discounting, most of them would cancel each other.

${ }^{15}$ NYMEX NG futures contracts refer to 10,000 million BTU. Prices, though, are quoted for 1 million BTU; this figure amounts to 1,055 GJ.

${ }^{16}$ See, among others, Schwartz [23], Baker, Mayfield and Parsons [1], Cortazar and Schwartz [8]. This behaviour is not consistent with a GBM model.
} 


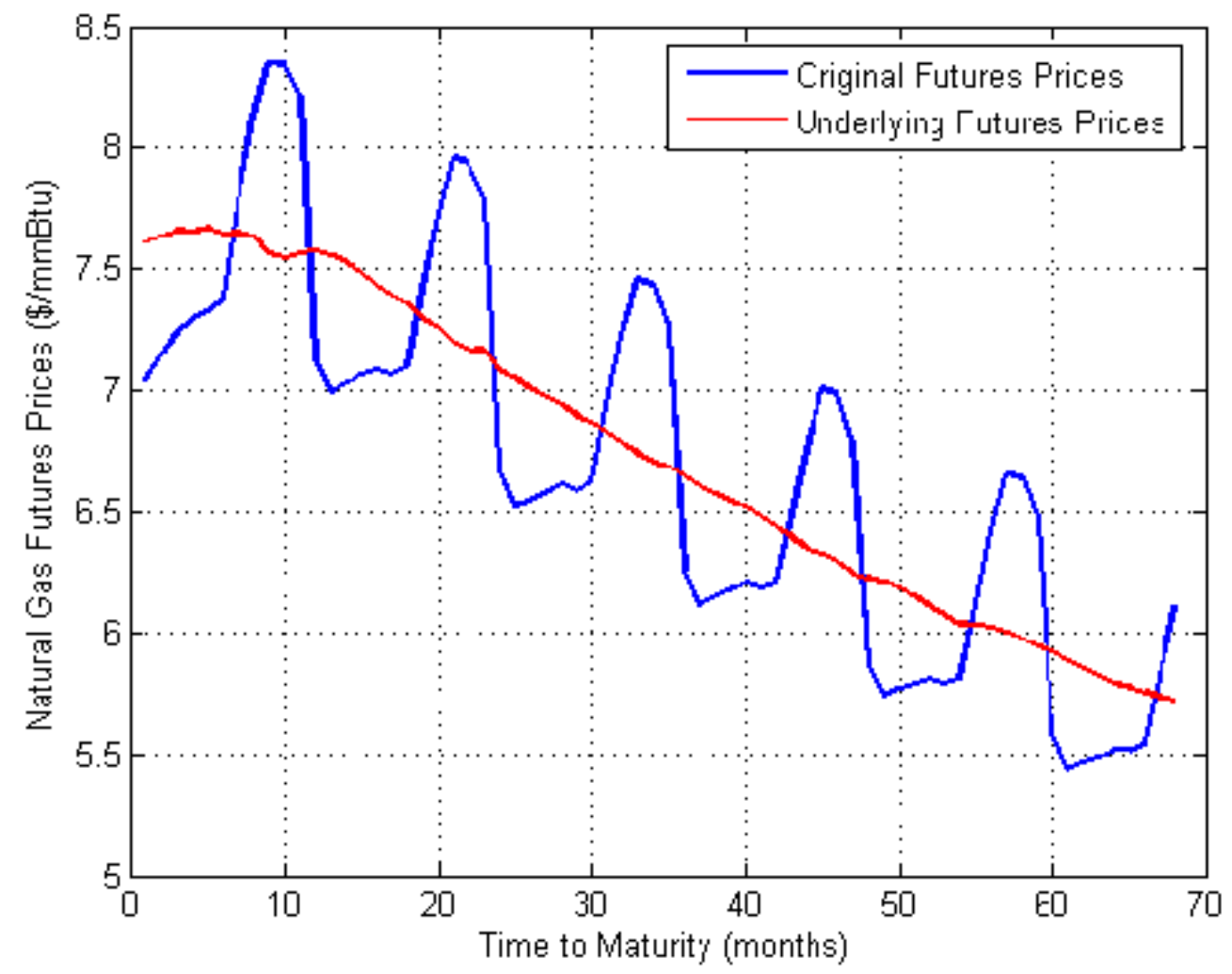

Figure 1: Nymex NG futures prices on 2005/04/19 and deseasonalised series. 


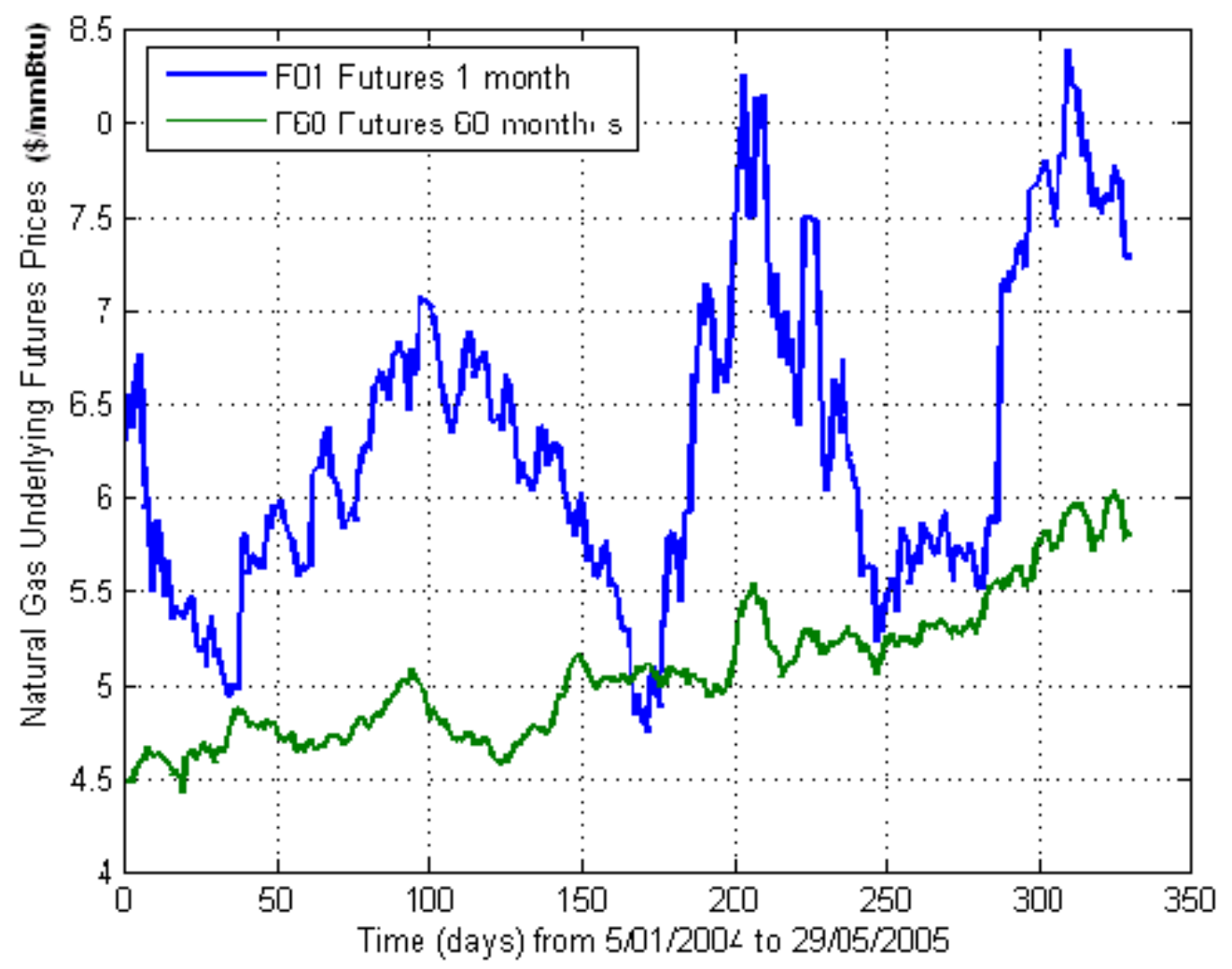

Figure 2: Nymex deseasonalised futures prices with one month (F01) and five years (F60) to expiry. 
state variables for each day. The choice of this method has to do with the nonlinearity of equation (11) and the unequal number of futures prices in which the market has not operated.

We have seven general parameters in the model: $k_{g}, \lambda_{g}, \lambda_{l}, \sigma_{g}, \xi, \mu$ and $L_{g}$. Nonetheless, given the optimization procedure chosen, mere observation of expression (11) leads to the conclusion that only the following combinations may be estimated: ${ }^{17}$

$$
\begin{gathered}
V_{1} \equiv k_{g}+\lambda_{g} \sigma_{g} \\
V_{2} \equiv \mu+\lambda_{l} \xi \\
V_{3} \equiv \mu k_{g} L_{g} .
\end{gathered}
$$

On the other hand, $L_{0}$ is a state variable for each day, but only the product $k_{g} L_{0}$ on each trading day $i$ can be estimated by the procedure adopted, i.e.:

$$
U_{i} \equiv k_{g} L_{0_{i}} .
$$

If we have price quotes in $N$ days ${ }^{18} t_{i}$, with $i=1,2, \ldots, N$, and on each day there are $M_{i}$ different contracts, with no reason why there must be the same number of price quotes every day, the function to be minimised is:

$$
\sum_{i=1}^{N} \sum_{j=1}^{M_{i}}\left(\hat{F}_{i j}\left(V_{1}, V_{2}, V_{3}, U_{i}, T_{j}-t_{i}, F_{i 1}\right)-F_{i j}\right)
$$

where $F_{i j}$ denotes the futures quote on day $i$ with maturity in (month) $j$, and $\hat{F}_{i j}$ stands for the contract price when this is estimated by means of expression (11) as a function of the parameters used $\left(V_{1}, V_{2}, V_{3}\right)$, the state variables $U_{i}$ for each day $i$, and time $T_{j}-t_{i}$ which is the difference (in years) between the futures contract maturity $T_{j}$ and the date of the first futures contract on day $i$ (assumed to be that for one month; this is $F_{i 1}$ futures contract, which is used as the spot price).

The estimation procedure involves two steps which are repeated until the sum of square errors converges:

a) A set of initial parameter values $\Omega=\left\{V_{1}, V_{2}, V_{3}\right\}$ is chosen. Then it is possible to estimate the state variables on each day in a single step:

$$
\left\{U_{1}, U_{2, \ldots,}, U_{N}\right\} \in \underset{U_{1}, U_{2}, \ldots, U_{N}}{\operatorname{argmin}} \sum_{i=1}^{N} \sum_{j=1}^{M_{i}}\left(\hat{F}_{i j}\left(V_{1}, V_{2}, V_{3}, U_{i}, T_{j}-t_{i}, F_{i 1} ; \Omega\right)-F_{i j}\right) .
$$

\footnotetext{
${ }^{17}$ The particular values of the seven original parameters of the model should also take into account the behaviour of the original time series.

${ }^{18}$ In our case, initially the whole sample of 330 days would be used up.
} 


\begin{tabular}{|c|c|c|c|}
\hline Concept & Panel I & Panel II & Panel III \\
\hline $\mathrm{N}^{o}$ Days & 330 & 100 & 50 \\
\hline $\mathrm{N}^{o}$ Observations & 23571 & 6989 & 3436 \\
\hline Sum of Square Errors & 405.47 & 32.02 & 15.82 \\
\hline Sum of Square Errors / Days & 1.2287 & 0.3202 & 0.3164 \\
\hline$V_{1}$ & 0.2122 & 0.1393 & 0.1283 \\
\hline$V_{2}$ & 2.5338 & 6.0412 & 6.1852 \\
\hline$V_{3}$ & 2.1346 & 2.9469 & 2.5870 \\
\hline$\hat{F}_{\infty}$ & 3.9704 & 3.5025 & 3.2604 \\
\hline
\end{tabular}

Table 1: Risk Neutral parameters.

b) The next step consists in estimating the values of the model parameters:

$$
\left\{V_{1}, V_{2}, V_{3}\right\} \in \underset{V_{1}, V_{2}, V_{3}}{\operatorname{argmin}} \sum_{i=1}^{N} \sum_{j=1}^{M_{i}}\left(\hat{F}_{i j}\left(V_{1}, V_{2}, V_{3}, U_{i}, T_{j}-t_{i}, F_{i 1} ; \Omega\right)-F_{i j}\right) .
$$

Table 1 shows the results obtained using the whole sample, the last one hundred days, and the last fifty days.

Figure 3 shows actual market data on 2005/04/19 as compared with the results of the models estimated with observations from 330 and 100 days. As will be shown below, in our case study the time to build natural gas plants is assumed to range from 30 to 36 months. Interestingly, for contract maturities of 30 months or more, the series of market futures prices and model (100 days) futures prices seem to agree most.

Figure 4 shows, also for 2005/04/19, the comparison between actual futures prices and those predicted in the long run. Note the trend in the longer term, where $\hat{F}_{\infty}=3,5025$. In sum, actual futures quotes from natural gas contracts seem rather consistent with the model adopted. ${ }^{19}$

In order to estimate the reamining paramerters, which are necessary for Monte Carlo simulations, the series obtained for the values of $G_{t}$ and $U_{t} \equiv k L_{0_{t}}$ will be used up, according to the following discretization:

$$
\frac{G_{t+\Delta t}-G_{t}}{G_{t}}=\frac{k_{g}\left(L_{t}-G_{t}\right) \Delta t}{G_{t}}+\sigma_{g} \epsilon_{t}^{G}
$$

where $\epsilon_{t}^{G}$ is an iid $\sim N(0,1)$ variate. This allows to compute $k_{g}$ by a process of square errors minimization or by OLS. $\sigma_{g}$ is computed from the residuals' standard deviation, once $k_{g}$ has been obtained. With this value it is possible to get the series $L_{0_{i}}$.

\footnotetext{
${ }^{19}$ It is necessary to stress the lower liquidity of futures contracts as the time to maturity increases, and the fact that there are no quotes for terms longer than six years.
} 


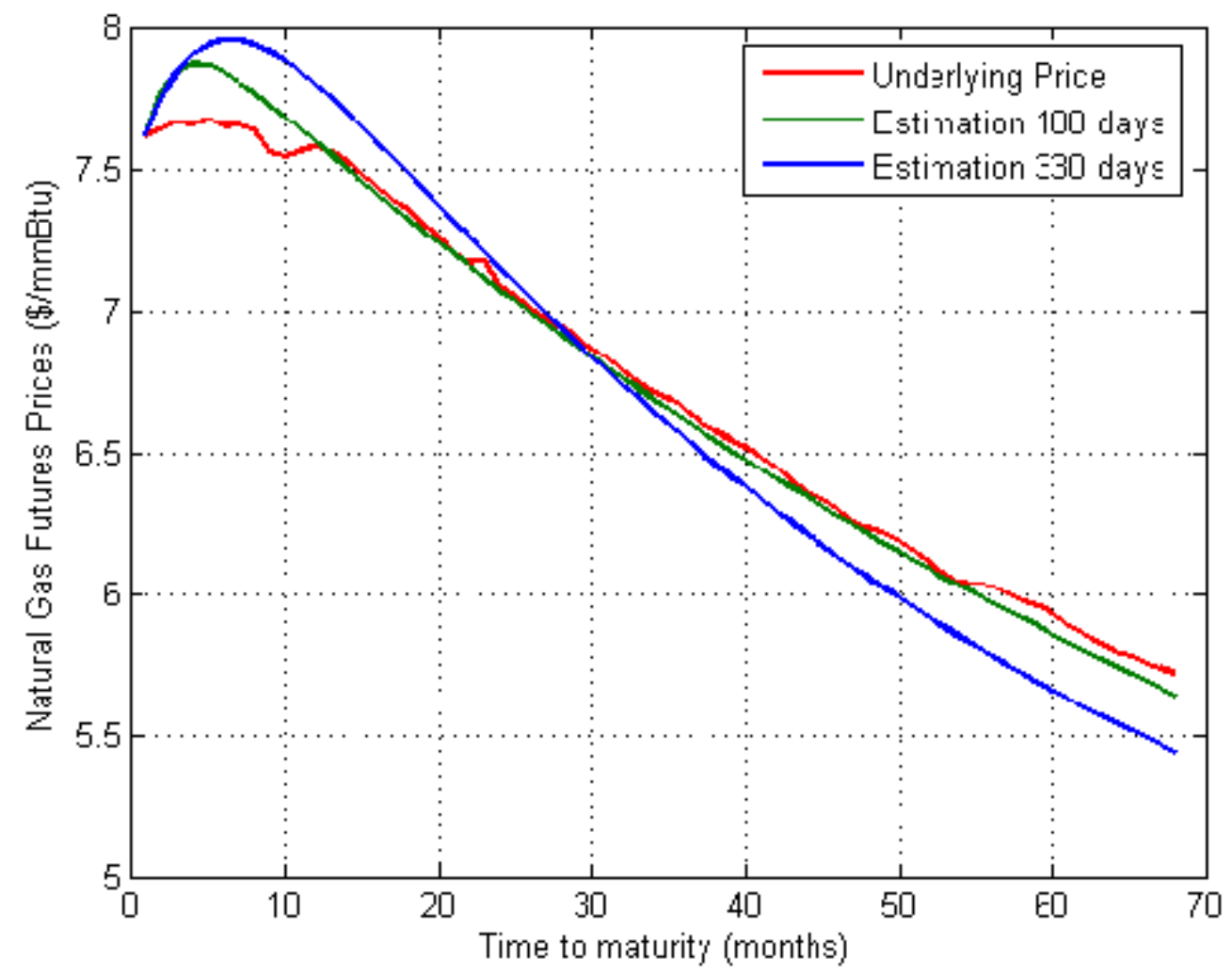

Figure 3: Actual (deseasonalised) futures prices on 2005/04/19 against theoretical values from estimated models. 


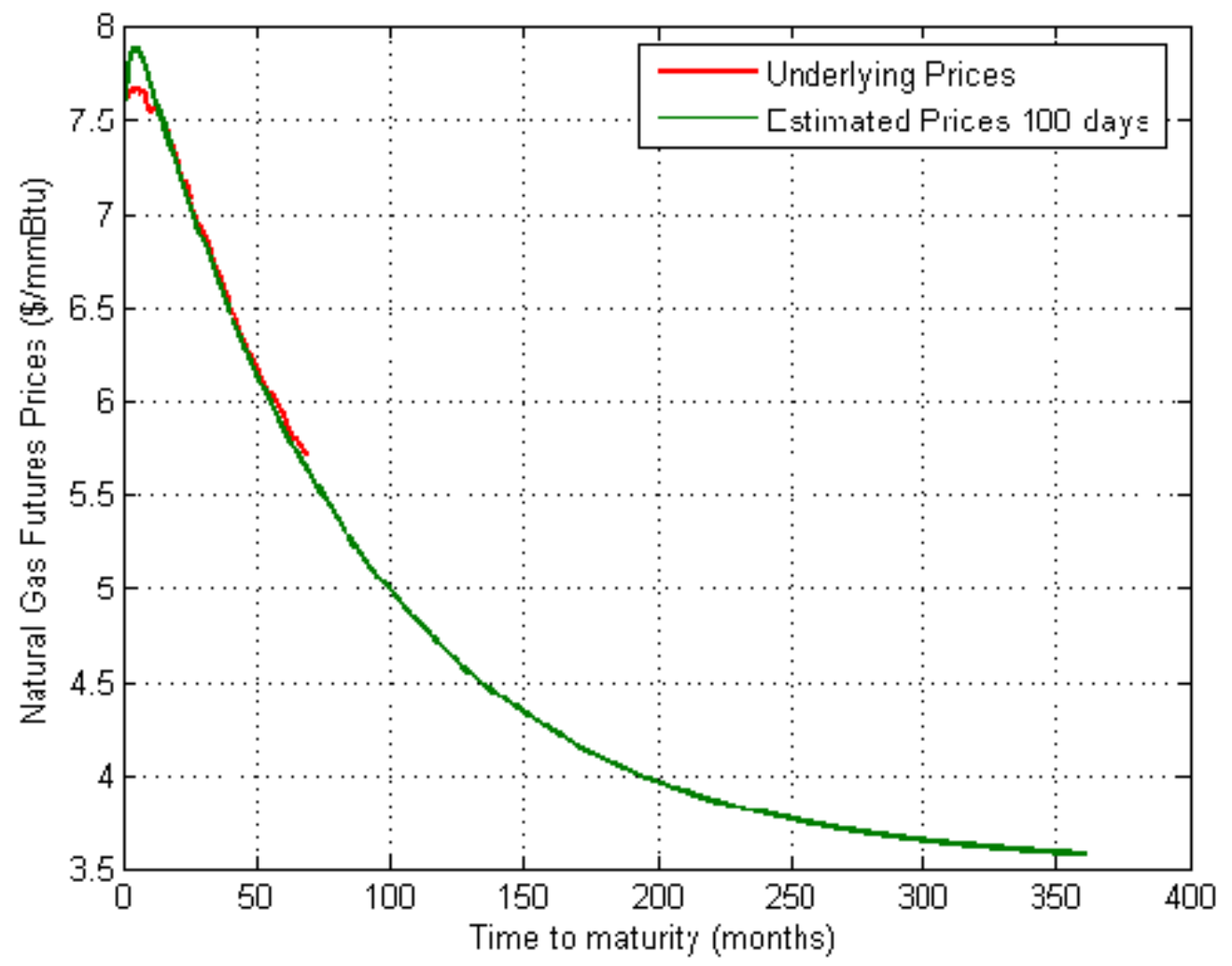

Figure 4: Actual (deseasonalised) futures prices on 2005/04/19 and those predicted in the long run. 
Similarly, once we know the value of $\mu L_{g}$ we can use

$$
\frac{L_{t+\Delta t}-L_{t}}{L_{t}}=\frac{\mu\left(L_{g}-L_{t}\right) \Delta t}{L_{t}}+\xi \epsilon_{t}^{L}
$$

where $\epsilon_{t}^{L}$ is an iid $\sim N(0,1)$ variate. Then, following similar procedures, the values of $\mu \mathrm{y} \xi$ are isolated, which allows to deduce $L_{g}$. Last, it is easy to deduce the value of the risk premia $\lambda_{g}$ and $\lambda_{l}$.

Table 2 summarizes the results:

\begin{tabular}{|c|c|}
\hline Parameter & Value \\
\hline$k_{g}$ & 0.3818 \\
\hline$\sigma_{g}$ & $43.44 \%$ \\
\hline$\mu$ & 4.1492 \\
\hline$\xi$ & $43.66 \%$ \\
\hline$\lambda_{g}$ & -0.5583 \\
\hline$\lambda_{l}$ & 4.3330 \\
\hline$L_{g}$ & 1.8603 \\
\hline
\end{tabular}

Table 2: Real parameters.

\subsection{Calibrated model for electricity price}

The data set consists of 95 monthly average electricity prices from the Spanish wholesale spot market (OMEL). ${ }^{20}$ They time span goes from January 1998 to October 2005, as shown inFigure 5.

Table 3 displays some basic statistics from the mean prices series

\begin{tabular}{|c|c|}
\hline Average & 3.2879 \\
\hline Median & 2.9195 \\
\hline Minimum & 1.8250 \\
\hline Maximum & 6.6910 \\
\hline Standard deviation & 1.0451 \\
\hline Coeff. Variation & 0.31787 \\
\hline Skewness & 1.3264 \\
\hline Excess Kurtosis & 1.4949 \\
\hline
\end{tabular}

Table 3: Actual parameters from OMEL market.

\footnotetext{
${ }^{20}$ Since the aim of the paper concerns (long-lived) baseload plants, monthly average prices have been chosen.
} 


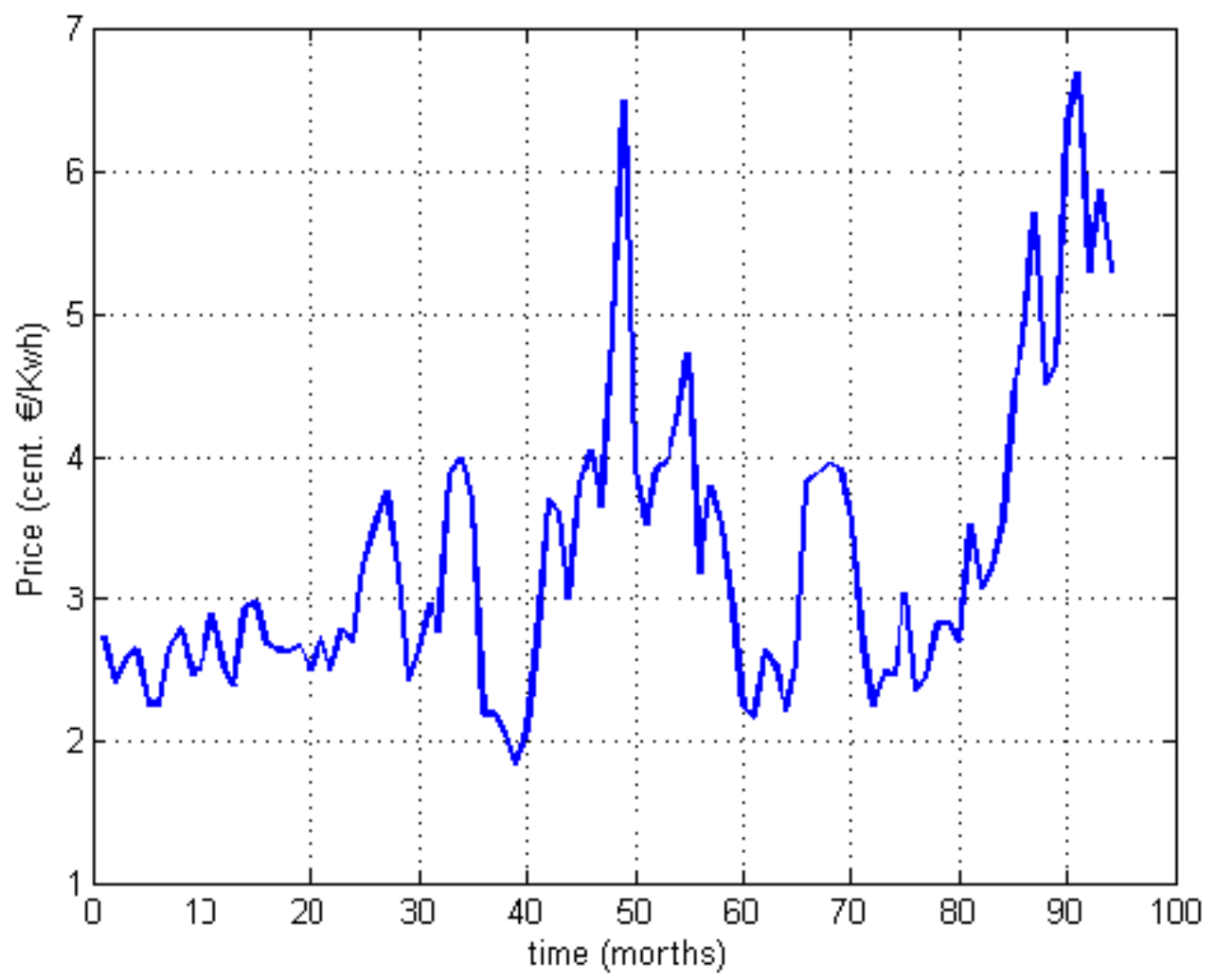

Figure 5: Monthly average electricity prices from Spanish OMEL market (January 1998 - October 2005). 
The following model is estimated:

$$
d E_{t}=k_{e}\left(L_{e}-E_{t}\right) d t+\sigma_{e} E_{t} d W_{t}^{E},
$$

which corresponds to an autorregresive model of order 1, or AR(1).

The partial autocorrelation function shown in Figure 6 is consistent with an AR(1) model.

Which, after discretization and rearranging, is:

$$
\frac{E_{t+1}-E_{t}}{E_{t}}=k_{e} L_{e} \Delta t \frac{1}{E_{t}}-k_{e} \Delta t+\sigma_{e} \epsilon_{t}^{E} .
$$

Expressed as $Y_{t}=\beta_{1}+\beta_{2} X_{2 t}+u_{t}$ and solved by OLS, we get the following estimates for $\hat{\beta}_{1}$ and $\hat{\beta}_{2}$ :

\begin{tabular}{|c|c|c|c|c|}
\hline Coefficient & Estim. value & Standard dev. & $t$-statistic & $p$-value \\
\hline$\hat{\beta}_{1}$ & -0.116136 & 0.0632336 & -1.8366 & 0.0695 \\
\hline$\hat{\beta}_{2}$ & 0.403814 & 0.186756 & 2.1623 & 0.0332 \\
\hline
\end{tabular}

$$
\begin{gathered}
\hat{\beta}_{1}=-0.116136=\frac{k_{e}}{12}, \\
\hat{\beta}_{2}=\frac{k_{e} L_{e}}{12}=\hat{\beta}_{1} L_{e} .
\end{gathered}
$$

The standard deviation of the residuals is 0.142427 . Hence $\sigma_{e}=0.142427 \times \sqrt{12}$ $=0.4934=49.34 \%$. It follows that:

\begin{tabular}{|c|c|}
\hline Parameter & Value \\
\hline$k_{e}$ & 1.3936 \\
\hline$L_{e}$ & 3.4771 \\
\hline$\sigma_{e}$ & 0.4934 \\
\hline
\end{tabular}

In our computations below, since there is no futures electricity market from which to infer a risk premium, we will assume $\lambda_{e}=0$; also, $\rho=0.55$.

\section{Case study}

\subsection{The NGCC plant}

The representative values used are shown in Table 4.

The Production Factor is the percentage of the total capacity used on average over the year. Using these data, the heat rate, the plant's consumption of energy, and the total production of electricity can be computed:

Heat Rate: $H R=3600 / R D T O / 1000000$, in GJ/Kwh. ${ }^{21}$

Investment Cost $I=1000 * i * P$, in Euros. ${ }^{22}$

\footnotetext{
${ }^{21}$ One Kwh amounts to $3.600 \mathrm{KJ}$, and one GJ (Gigajoules) is 1 million KJ (Kilojoules).
}

${ }^{22}$ Since power is measured in Mw. 
FAC de prred_des
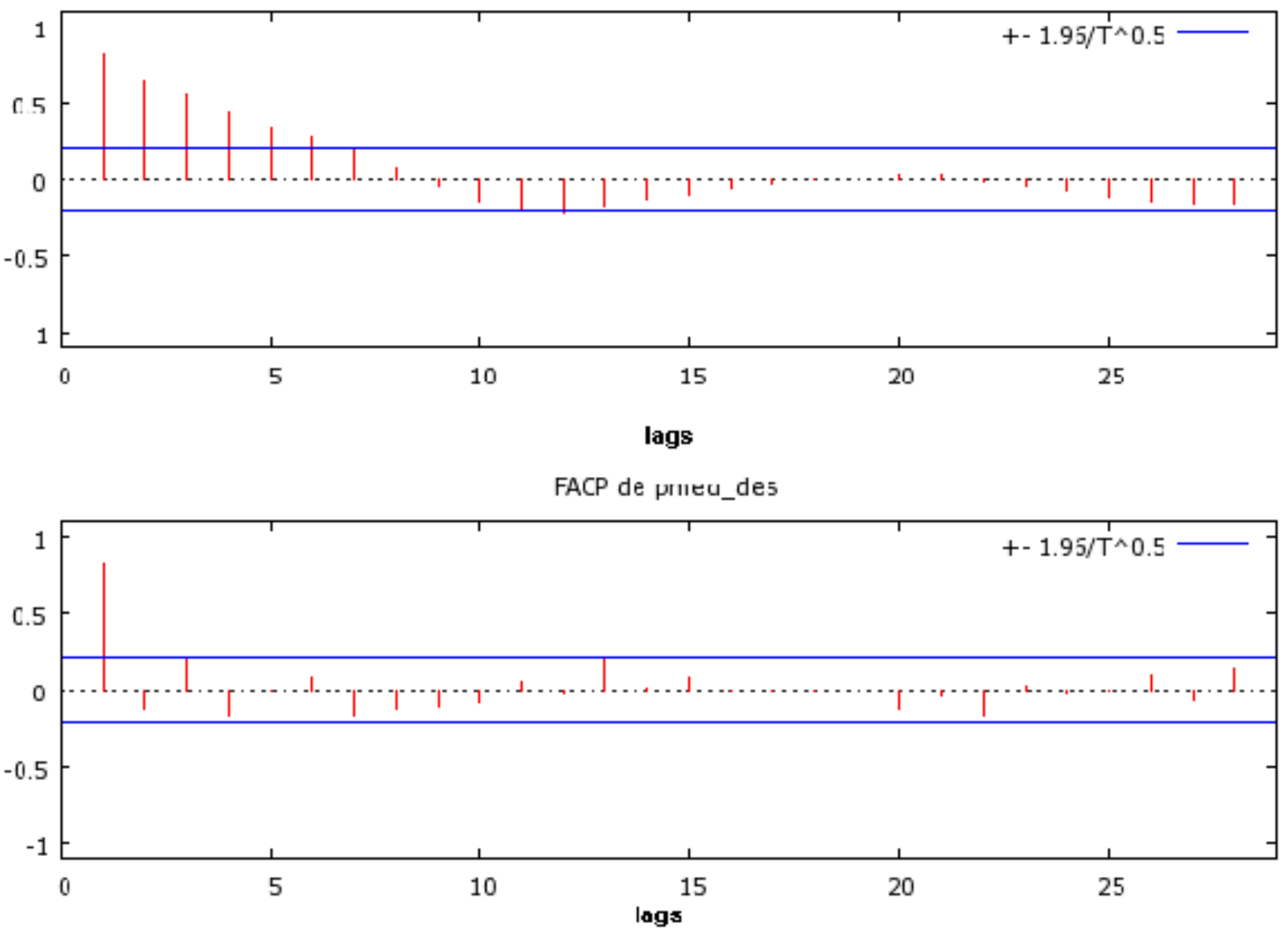

Figure 6: Partial autocorrelation function from (deseasonalised) average electricity price series. 


\begin{tabular}{|c|c|}
\hline Concept & Value \\
\hline Output Mw $\left(P_{N G C C}\right)$ & 500 \\
\hline Production Factor (\% Capacity) (FP) & $80 \%$ \\
\hline Net Efficiency (\%) (RDTO) & $55 \%$ \\
\hline Investment Cost (€/kw) (i) & 422,5 \\
\hline Useful Life (years) & 25 \\
\hline Time to Build (months) & 30 \\
\hline Necessary Surface $\left(\mathrm{m}^{2} / \mathrm{Mw}\right)$ & 100 \\
\hline Annual Maintenance (weeks) & 3.5 \\
\hline Time to Start $($ minutes $)$ & $15-60$ \\
\hline O \& M (cts.€/kwh) $(\mathrm{CVAR})$ & 0.32 \\
\hline Refrigeration Water $\left(\mathrm{m}^{3} / \mathrm{hMw}\right)$ & 7 \\
\hline
\end{tabular}

Table 4: Basic NGCC parameters.

\begin{tabular}{|c|c|}
\hline Concept & Value \\
\hline Heat Rate GJ/Kwh & 0.006545 \\
\hline Total Investment (million $€$ ) & 211.25 \\
\hline Annual production (million Kwh) & 3,504 \\
\hline Fuel Energy (GJ/year) & $22,935,273$ \\
\hline $\mathrm{CO}_{2}$ Emissions (tonne/year) & $1,226,400$ \\
\hline
\end{tabular}

Table 5: Resulting NGCC parameters.

Total annual production: $A=1000 P * 365 * 24 * F P$, in Kwh.

Fuel energy needs: $B=1000 P * 365 * 24 * F P * H R$, in GJ/year.

Yearly $C_{2}$ emissions: $E M=350 * A / 1000000$, in tonnes per year.

Now with these formulae we estimate the parameters in Table 5.

\subsection{The LNG Plant}

We consider a LNG plant with total capacity amounting to $200,000 \mathrm{Nm}^{3} / \mathrm{h}$ which is equivalent to 1,752 million $\mathrm{Nm}^{3}$ per year.

Under the assumption of $9,500 \mathrm{Kcal}$ for each $\mathrm{Nm}^{3},{ }^{23}$ this amount is equivalent to: ${ }^{24}$

$$
1,752,000,000 * 9500 * 0.000004186=69,671,784 G J
$$

This quantity amounts to $5,805,982 G J$ for each month in which the plant operates.

The representative values used are shown in Table 6 .

\footnotetext{
${ }^{23}$ We adopt an average of typical calorific values: 10,000 $\mathrm{Kcal}$ for natural gas with upper calorific power and $9,000 \mathrm{Kcal}$ for that of lower calorific power. $\mathrm{Nm}^{3}$ refers to volume measurements taken at normal conditions of $0{ }^{\circ} \mathrm{C}$ temperature and $1 \mathrm{~atm}$ pressure.

${ }^{24}$ One kilocalorie amounts to 0.000004186 GJ.
} 


\begin{tabular}{|c|c|}
\hline Concept & Value \\
\hline Output $\left(P_{L N G}\right)\left(\mathrm{Nm}^{3} / \mathrm{h}\right)$ & 200,000 \\
\hline Investment Cost (million $€)\left(I_{L N G}\right)$ & 318 \\
\hline Useful Life (years) & 30 \\
\hline Time to Build (months) & 36 \\
\hline Necessary Surface & $150,000 \mathrm{~m}^{2}$ \\
\hline Unit Variable Cost $\left(\$ /\right.$ million BTU $\left(C V A R_{L N G}\right)$ & 0.30 \\
\hline Fixed Cost (million $€ /$ year $)\left(C F I X_{L N G}\right)$ & 11.8 \\
\hline
\end{tabular}

Table 6: Basic LNG parameters.

Total investment cost is 318 million $€$. Fixed costs per month amount to $982,938 €$.

\section{Valuation of natural gas investments}

\subsection{The operating NGCC plant}

First we compute the value of an immediate investment in a NGCC power plant, which is designed to operate $80 \%$ of the time. Revenues come from the electricity produced; they are assumed to be stochastic. Costs include:

a) The initial outlay, which initially is assumed constant.

b) Variable costs, among them those due to the consumption of fuel, in our case natural gas), assumed stochastic.

c) Costs related to the emission of $\mathrm{CO}_{2}$ (tonnes); at present we assume they are deterministic.

The present value of revenues, for a finite number of periods (taking into account that there will be no production of electricity until the construction phase is completed and, therefore, it will only be in operation from time $\tau_{1}$ to $\tau_{2}$ ) is (see expression (65) in the Appendix):

$$
P V R=A\left[\frac{L_{e}}{r}\left(e^{-r \tau_{1}}-e^{-r \tau_{2}}\right)+\frac{E_{0}-L_{e}}{k_{e}+r}\left(e^{-\left(k_{e}+r\right) \tau_{1}}-e^{-\left(k_{e}+r\right) \tau_{2}}\right)\right],
$$

where:

$A=$ annual production: 3,504 million Kwh.

$E_{0}=$ current wholesale electricity price: $0.05286542 € / k w h$.(as of April-05, deseasonalised)

$L_{e}=$ long term equilibrium price: $0.034771 € / k w h$.

$k_{e}=$ speed of reversion for electricity price: 1.3936 .

$\tau_{1}=$ time to build: 2.5 years.

$\tau_{2}-\tau_{1}=$ useful life of the plant: 25 years.

$r=$ riskless interest rate: $5 \%$.

With these values, we get $P V R=1,535.51$ million $€$. 
Variable costs (other than the gas fired and the emission allowances) are computed as follows:

$$
P V C_{v a r}=A \cdot C_{v a r} \cdot \frac{e^{-r \tau_{1}}-e^{-r \tau_{2}}}{r-r_{b}},
$$

where $C_{\text {var }}$ denotes unit variable costs: $0.0032 € / k w h$. Using these data, we get $P V C_{\text {var }}=141.20$ million $€$.

The cost of $\mathrm{CO}_{2}$ emissions is assumed to be $C=10 € /$ tonne. This figure times $E M=1,226,400$ tonnes emitted per year, and applying a formual similar to (34) allow us to compute a present value of carbon costs $P V C=154.44$ million euros. ${ }^{25}$

As for the present value of natural gas, this is computed using the estimates from model II, taking as a base date the last day of the series $(2005 / 04 / 29): G_{0}$ $=7.2822 \$ /$ million BTU and $k L_{0}=4.2007$. The value of a unit of natural gas consumed from year 2.5 to year 27.5 is determined by formula (61) in the Appendix: $58.4867 \$ /$ million BTU fired per year. This figure amounts to 55.4376 $\$ /$ GJ, which translates into $42.7859 € /$ GJ for an exchange rate of $1.2957 \$ / €$. Given that 22,935,273 GJ/year are needed, the present value of total energy costs is $P V G=981.31$ million $€$.

In sum, the present value of an operating NGCC plant is:

$$
V\left(G_{0}, L_{0}, E_{0}\right)=P V R-P V C_{\text {var }}-P V G-P V C=258.56 \text { million } €
$$

This value includes the positive influence from the expected fall in natural gas price over the construction period of 30 months. It is a function of $G_{0}, L_{0}$ and $E_{0}$, ceteris paribus.

Since the initial disbursement amounts to $I=211.25$ million $€$, if the alternatives were to invest at that precise moment or not to invest, we would invest and get a net result of $V\left(G_{0}, L_{0}, E_{0}\right)-I=47.31$ million $€$.

\subsection{The operating LNG plant}

The above results are now used to value an operating LNG plant. We consider an initial situation in which the spread between domestic and foreign gas prices is $0.70 \$ / \mathrm{mmBtu}$, and that this difference reflects exactly transport costs of the natural gas to the consuming NGCC plant. ${ }^{26}$ Therefore, initially it is indifferent whether to use the LNG plant or not from the point of view of the fuel input; yet it would not be used because of variable costs. First we assume a correlation coefficient of $0.75 \%$ between domestic and foreign gas prices. Also, the decision to fire one kind of gas or the other is taken on a monthly basis.

The risk-neutral model is:

\footnotetext{
${ }^{25}$ It is assumed that initially the plant has no emission permit, unlike incumbent plants under their National Allocation Plans.

${ }^{26}$ In other words, initially the import price plus transport costs just equal the domestic price. From then on, each gas reasource evolves on its own.
} 


$$
\begin{gathered}
d \hat{S}_{t}^{d}=\left[k\left(\hat{L}_{t}^{d}-\hat{S}_{t}^{d}\right)-\lambda_{g} \sigma \hat{S}_{t}^{d}\right] d t+\sigma \hat{S}_{t}^{d} d W_{t}^{d G}, \\
d \hat{L}_{t}^{d}=\left[\mu\left(L E^{d}-\hat{L}_{t}^{d}\right)-\lambda_{l} \xi \hat{L}_{t}^{d}\right] d t+\xi \hat{L}_{t}^{d} d W_{t}^{d L}, \\
d \hat{S}_{t}^{f}=\left[k\left(\hat{L}_{t}^{f}-\hat{S}_{t}^{f}\right)-\lambda_{g} \sigma \hat{S}_{t}^{f}\right] d t+\sigma \hat{S}_{t}^{f} d W_{t}^{f G}, \\
d \hat{L}_{t}^{f}=\left[\mu\left(L E^{f}-\hat{L}_{t}^{f}\right)-\lambda_{l} \xi \hat{L}_{t}^{f}\right] d t+\xi \hat{L}_{t}^{f} d W_{t}^{f L}, \\
\rho_{W^{d G} W^{f G}}=0.75
\end{gathered}
$$

with the remaining correlation coefficients assumed to equal 0.

Each month, the LNG provides a net cash flow:

$$
C F=e^{-\frac{r}{24}}\left[\max \left(\left(\frac{B}{12}\left(\hat{S}_{t}^{d}-\hat{S}_{t}^{f}-0.2195\right), 0\right)-982,938\right]\right.
$$

where $B=69,671,784$ GJ is the amount of energy processed at the plant in a year if it operates every month. We are assuming that the cash flow is obtained at the middle point of each monthly period; thus it must be discounted over half a month.

A variable cost of $0.30 \$ / \mathrm{mmBtu}$ is assumed; this is equivalent to 0.2195 $€ /$ GJ. ${ }^{27}$ Variable costs are only incurred if the LNG plant operates in that period. 982,938 is $1 / 12$ of yearly fixed costs. Under the assumption of a useful life of 30 years, there are 360 monthly periods in which to compute the cash flows. Discounted at the risk-free interest rate $r=0.05$, these will give us the present value of the plant; for this to be profitable, the value must be higher than the building costs which are disbursed 36 months before starting operation.

The LNG plant's gross and net presente values (in million euros) as a function of the correlation coefficient appears in Table 7.

\begin{tabular}{|c|c|c|}
\hline$\rho_{W^{d G} W^{f G}}$ & GPV LNG & NPV LNG \\
\hline 0.65 & 948.54 & 630.54 \\
\hline 0.70 & 867.02 & 549.02 \\
\hline 0.75 & 776.80 & 458.80 \\
\hline 0.80 & 675.24 & 357.24 \\
\hline 0.85 & 557.98 & 239.98 \\
\hline
\end{tabular}

Table 7: Gross and net Value of a LNG plant as a function of the correlation coefficient between domestic and foreighn gas prices.

As could be expected, when the correlation between domestic and foreign natural gas prices decreases the LNG plant becomes more valuable.

\footnotetext{
${ }^{27}$ We use the relation $1 \mathrm{MBtu}=1,055 \mathrm{GJ}$ and an exchange rate $1.2957 \$ / €$.
} 


\section{Options on a baseload NGCC plant}

\subsection{Value of a finite-lived option to double plant size}

Let us consider a firm which now can build a plant of size $X$ and decide to build another one of equal size in the next five years. ${ }^{28}$ In order to value this opportunity we run 30,000 Monte Carlo simulations for each one of the 500 regularly distributed dates from year 0 to year 5 . Any simulation run fits the discretized equations (16), (17) and (18). Depending on the specific values of the correlation coefficients, the Monte Carlo simulation technique may require the generation of two or more correlated Normal variates. In our case, we assume $\rho_{G, L}=\rho_{L, E}=0.0$, but $\rho_{G, E}=0.55$; also, we adopt $\Delta t=0.01$.

The series obtained for $\hat{G}_{t}, \hat{L}_{t}$ and $\hat{E}_{t}$ allow to compute at any time the value $V_{t}$ of an investment at that time, taking into account the evolution of electricity and gas prices, as well as the behaviour of the equilibrium gas price in the short term $\left(\hat{L}_{t}\right)$. Apart from the initial outlay (which is disbursed at the time of the investment), all other costs and revenues are due starting 2.5 years later. ${ }^{29}$

Given the values of $V_{t}$ at any moment and in each path, the Least Squares MonteCarlo (LSM) approach is used. ${ }^{30}$ At the last moment, the value of the investment in each path is:

$$
\max \left(V\left(G_{T}, L_{T}, E_{T}\right)-I, 0\right) .
$$

At earlier moments, the method is based on the computation of a series of parameters that allow to construct a linear combination of basic functions. This combination allows to estimate at each step the continuation value. The specification adopted consists of a second-order expected continuation value function with 10 regressors (since there are 3 sources of risk), namely: ${ }^{31}$

$$
\begin{aligned}
& E_{i}^{Q}\left[e^{-r \Delta t} V_{i+1}\left(\hat{G}_{i+1}, \hat{L}_{i+1}, \hat{E}_{i+1}\right)\right] \approx a_{1}+a_{2} \hat{G}_{i}+a_{3} \hat{G}_{i}^{2}+ \\
& \quad+a_{4} \hat{L}_{i}+a_{5} \hat{L}_{i}^{2}+a_{6} \hat{E}_{i}+a_{7} \hat{E}_{i}^{2}+a_{8} \hat{G}_{i} \hat{L}_{i}+a_{9} \hat{G}_{i} \hat{E}_{i}+a_{10} \hat{L}_{i} \hat{E}_{i} .
\end{aligned}
$$

At any time, considering the paths that are in-the-money and by ordinary least squares, we can get the value of the 10 coefficients. ${ }^{32}$

\footnotetext{
${ }^{28}$ As before, in case the firm decides to invest, building the new plant takes time, namely 2.5 years.

${ }^{29}$ Previously we have checked the convergence of the average price for a long term, say $\hat{G}_{27,5}$, towards the expected futures price for that specific date; this can be computed analytically and happens to be $3,5983 € /$ GJ.

${ }^{30}$ See Longstaff and Schwartz [15] for a description of this method.

${ }^{31}$ Cortazar, Gravet and Urzua [6] propose using powers of expected spot prices instead of functional forms of the state variables. The rationale for this is that, in many cases, optimal exercise depends on expected spot prices and volatilities. They successfully implement their method in an extended version of Brennan and Schwarz [4] model.

${ }^{32}$ The optimal exercise frontier would be given by a surface formed with those values of $\hat{G}_{i}$, $\hat{L}_{i}$ and $\hat{E}_{i}$ that satisfy the following condition: $V_{i}\left(\hat{G}_{i}, \hat{L}_{i}, \hat{E}_{i}\right)=a_{1}+a_{2} \hat{G}_{i}+a_{3} \hat{G}_{i}^{2}+a_{4} \hat{L}_{i}+$ $a_{5} \hat{L}_{i}^{2}+a_{6} \hat{E}_{i}+a_{7} \hat{E}_{i}^{2}+a_{8} \hat{G}_{i} \hat{L}_{i}+a_{9} \hat{G}_{i} \hat{E}_{i}+a_{10} \hat{L}_{i} \hat{E}$, that is, the values for which the present value of investing at that time $i$ equals the continuation value.
} 
The valuation results are shown in Figure 7; as can be noted, the value of this option increases with the maturity of the option.

The most significant values are displayed in Table 8.

\begin{tabular}{|c|c|c|}
\hline Maturity (years) & Option Value $($ million $€$ ) & Project Total Value \\
\hline 0.00 & 47.31 & 94,62 \\
\hline 1.00 & 111.37 & 158.68 \\
\hline 2.00 & 144.26 & 191.57 \\
\hline 3.00 & 167.15 & 214.46 \\
\hline 4.00 & 183.46 & 230.77 \\
\hline 5.00 & 195.48 & 242.79 \\
\hline
\end{tabular}

Table 8: Value of the option to decide doubling the plant size.

With 5 years to decide doubling the plant size, the value of the option increases to 195.48 million $€$; it benefits from the expected decline in gas prices and from a lower present value of the initial disbursement. Project's total value, i.e. the net value of the initial investment in an operating plant plus the option to double plant size, results from adding 47.31 million $€$ to the above series. With 5 years ahead, project's total value is 242.79 million $€$, some 150 million $€$ above the value of building two lower-sized plants at the initial moment.

If it is compared with a project to invest in a double-sized plant, with a $10 \%$ saving in building costs and a higher efficiency of $57 \%$, the project's value amounts to 205.72 million $€$; this is more than the value of investing initially in two smaller plants, but less than the value of a modular project, when the option to invest has a maturity of 3 or more years.

\subsection{Value of the option to invest when the initial invest- ment cost $I$ is stochastic}

Consider now a stochastic initial investment $I$ according to the following equation:

$$
d I_{t}=\alpha_{I} I_{t} d t+\sigma_{I} I_{t} d W_{t}^{I}
$$

with the traditional meaning for each variable and $\rho_{W^{I} W^{G}}=\rho_{W^{I} W^{L}}=\rho_{W^{I} W^{E}}$ $=0$.

The risk-adjusted version would be:

$$
d \hat{I}_{t}=\left(\alpha_{I}-\lambda_{I} \sigma_{I}\right) \hat{I}_{t} d t+\sigma_{I} \hat{I}_{t} d W_{t}^{I} .
$$

After discretization:

$$
\Delta \hat{I}_{t}=\left(\alpha_{I}-\lambda_{I} \sigma_{I}\right) \hat{I}_{t} \Delta t+\sigma_{I} \hat{I}_{t} \sqrt{\Delta t} \epsilon_{t}^{I},
$$




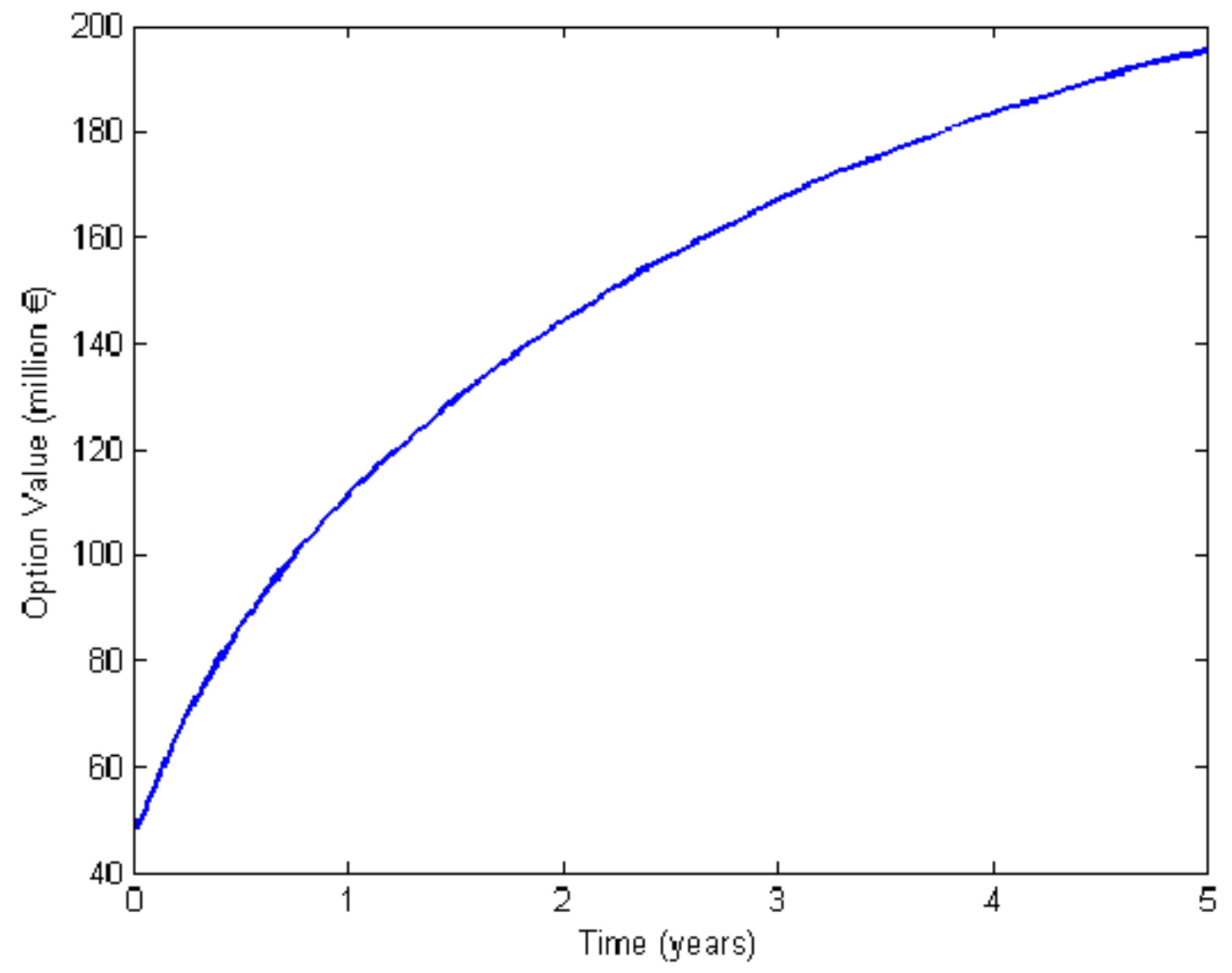

Figure 7: Value of the option to invest as a function of the option's maturity. 
where $\epsilon_{t}^{I} \sim N(0,1)$.

We analyse the case in which $\alpha_{I}-\lambda_{I} \sigma_{I}=0, \Delta t=0.01$ and $\sigma_{I}=0.30 .{ }^{33}$ For each of the 30,000 paths of $\hat{G}_{t}, \hat{E}_{t}$ and $\hat{L}_{t}$ we get a path for $\hat{I}_{t} \cdot{ }^{34}$. This will allow to estimate, at each moment, the value of an immediate investment and hence what paths are at-the-money at that precise time. For the option with 5 years to maturity we compute a value of 204.38 million $€$, a figure which is slightly above the 195.48 million $€$ estimated above. Table 9 shows the value of the option to invest as a function of initial investment's volatility.

\begin{tabular}{|c|c|}
\hline Volatility $\left(\sigma_{I}\right)$ & Option Value (million $€$ ) \\
\hline 0.00 & 195.48 \\
\hline 0.10 & 195.59 \\
\hline 0.20 & 198.26 \\
\hline 0.30 & 204.38 \\
\hline 0.40 & 214.53 \\
\hline 0.50 & 226.73 \\
\hline 0.60 & 239.87 \\
\hline 0.70 & 253.23 \\
\hline 0.80 & 266.02 \\
\hline 0.90 & 278.17 \\
\hline 1.00 & 289.45 \\
\hline
\end{tabular}

Table 9: Vaue of the option to invest in 5 years with stochastic building costs.

\subsection{Value of the option to invest when the cost of $\mathrm{CO}_{2}$ emissions is stochastic}

Now consider that the cost of $\mathrm{CO}_{2}$ emissions is stochastic and follows the process:

$$
d C_{t}=\alpha_{C} C_{t} d t+\sigma_{C} C_{t} d W_{t}^{C}
$$

with the usual meaning for each variable and $\rho_{W^{C} W^{G}}=\rho_{W^{C} W^{L}}=\rho_{W^{C} W^{E}}=$ $\rho_{W^{C} W^{I}}=0$.

The risk-neutral version would be:

$$
d \hat{C}_{t}=\left(\alpha_{C}-\lambda_{C} \sigma_{C}\right) \hat{C}_{t} d t+\sigma_{C} \hat{C}_{t} d W_{t}^{C}
$$

After discretization:

$$
\Delta \hat{C}_{t}=\left(\alpha_{C}-\lambda_{C} \sigma_{C}\right) \hat{C}_{t} \Delta t+\sigma_{C} \hat{C}_{t} \sqrt{\Delta t} \epsilon_{t}^{C} .
$$

\footnotetext{
${ }^{33}$ With this volatility, one year from now the initial investment will range between $-30 \%$ and $+30 \%$ times the current amount with a probability of $68.27 \%$ (approximately $2 / 3$ ).

${ }^{34}$ Obviously at every time the average of the 30,000 simulations must be 211.25 million $€$.
} 
where $\epsilon_{t}^{C} \sim N(0,1)$.

Next we compute the value of the option to invest up to five years ahead for different values of emission permits' volatility and two possible values for $\left(\alpha_{C}-\lambda_{C} \sigma_{C}\right)$, namely 0 and $r$.

Given an initial level $C_{0}$, the expected value at time $t$ under the risk-neutral probability measure is:

$$
E\left(\hat{C}_{t}\right)=C_{0} e^{\left(\alpha_{C}-\lambda_{C} \sigma_{C}\right) t} .
$$

The value of an annuity between time $\tau_{1}$ and time $\tau_{2}$ is determined by:

$$
V_{\tau_{1}, \tau_{2}}^{c}=\int_{\tau_{1}}^{\tau_{2}} E\left(\hat{C}_{t}\right) e^{-r t} d t
$$

which gives:

$$
V_{\tau_{1}, \tau_{2}}^{c}=\frac{C_{0}}{\alpha_{C}-\lambda_{C} \sigma_{C}-r}\left[e^{\left(\alpha_{C}-\lambda_{C} \sigma_{C}-r\right) \tau_{2}}-e^{\left(\alpha_{C}-\lambda_{C} \sigma_{C}-r\right) \tau_{1}}\right] .
$$

The total cost comes from multiplying this amount times 1,226,400 tonnes of $\mathrm{CO}_{2}$ per year. Consider two situations:

a) When $\left(\alpha_{C}-\lambda_{C} \sigma_{C}\right)=0$ we have:

$$
V_{\tau_{1}, \tau_{2}}^{c}=\frac{C_{0}}{-r}\left[e^{-r \tau_{2}}-e^{-r \tau_{1}}\right] .
$$

With $C_{0}=10 € /$ tonne, $\tau_{1}=2.5$ and $\tau_{2}=27.5$ this amounts to a cost of 125.93

$€ /$ tonne, which corresponds to a present value of total emission cost of 154.44 million, the same figure as in the base case.

b) When $\left(\alpha_{C}-\lambda_{C} \sigma_{C}\right)=r=0.05$ we have an annuity value

$$
V_{\tau_{1}, \tau_{2}}^{c}=C_{0}\left[\tau_{2}-\tau_{1}\right] .
$$

With $C_{0}=10 € /$ tonne, $\tau_{1}=2.5$ and $\tau_{2}=27.5$ this gives a cost of 250.00 $€ /$ tonne, which corresponds to a present value of total emission cost of 306.60 million $€$.

Now the difference in both cases is that these values are not fixed. Instead, they depend on the initial value $C_{0}$ at each moment and which is obtained by Monte Carlo simulations. The value of the option to invest (in million euros) is shown in Table 10.

When the expected groth rate of emission costs is $0 \%$, the option values obtained are a bit higher than in the base case, whereas they are significantly lower with an expected growth rate of $5 \%$.

\subsection{Value of the option to invest when its maturity is sto- chastic}

Here we consider the case in which the option to invest has a stochastic time to maturity. This means that there is a probability $\lambda$ that it will disappear in 


\begin{tabular}{|c|c|c|}
\hline Maturity (years) & Option Value (0\%) & Option Value (5\%) \\
\hline 0.00 & 47.31 & 0.00 \\
\hline 0.50 & 87.41 & 16.50 \\
\hline 1.00 & 113.08 & 34.31 \\
\hline 1.50 & 131.58 & 47.94 \\
\hline 2.00 & 146.72 & 58.73 \\
\hline 2.50 & 159.09 & 68.14 \\
\hline 3.00 & 169.78 & 76.59 \\
\hline 3.50 & 178.69 & 83.28 \\
\hline 4.00 & 186.76 & 89.51 \\
\hline 4.50 & 193.85 & 94.91 \\
\hline 5.00 & 199.56 & 99.76 \\
\hline
\end{tabular}

Table 10: Vaue of the option to invest in 5 years with stochastic CO2 emission costs.

one year; thus the probability to disappear during a period $d t$ is $\lambda d t$. Anyway, we assume that the opportunity to invest vanishes at the end of the fifth year. Also, as soon as the option expires, the value of the project becomes 0 .

Random samples from a Poisson distribution with parameter $\lambda$ are drawn to get the moment at which the right to invest ceases; given the value of the project at each simulation run the LSM approach is used; these values will be 0 if the option to invest has disappeared. In other words, the continuation value takes into account the chance that waiting for a moment the option to invest vanishes.

Figure (8) shows the value of the option to invest as a function of the probability $\lambda$ and the option's maturity.

For low probabilities $\lambda$, the values of the option are slightly lower than in the base case. For very high values of $\lambda$, the value approaches 47.31 million $€$, which happens to be the option's value when the only decision is whether to invest at the initial moment or not.

\section{Concluding remarks}

This paper evaluates investments in natural gas plants. Our first example is a plant which burns gas to produce electricity by means of a combined cycle; the second one is a plant for storing gas depending on the price gap between domestic and foreign gas resources (or as a move towards greater diversification due to energy security concerns). The fact that these plants take time to build is explicitly modelled. Also, the recent operation of the EU Emmission Trading Scheme has brought a new commodity, carbon, that will have an impact on energy investments, at least for European utilities.

We assume that both natural gas and electricity prices follow mean-reverting stochastic processes, namely an Inhomogenous Geometric Brownian Motion. We 


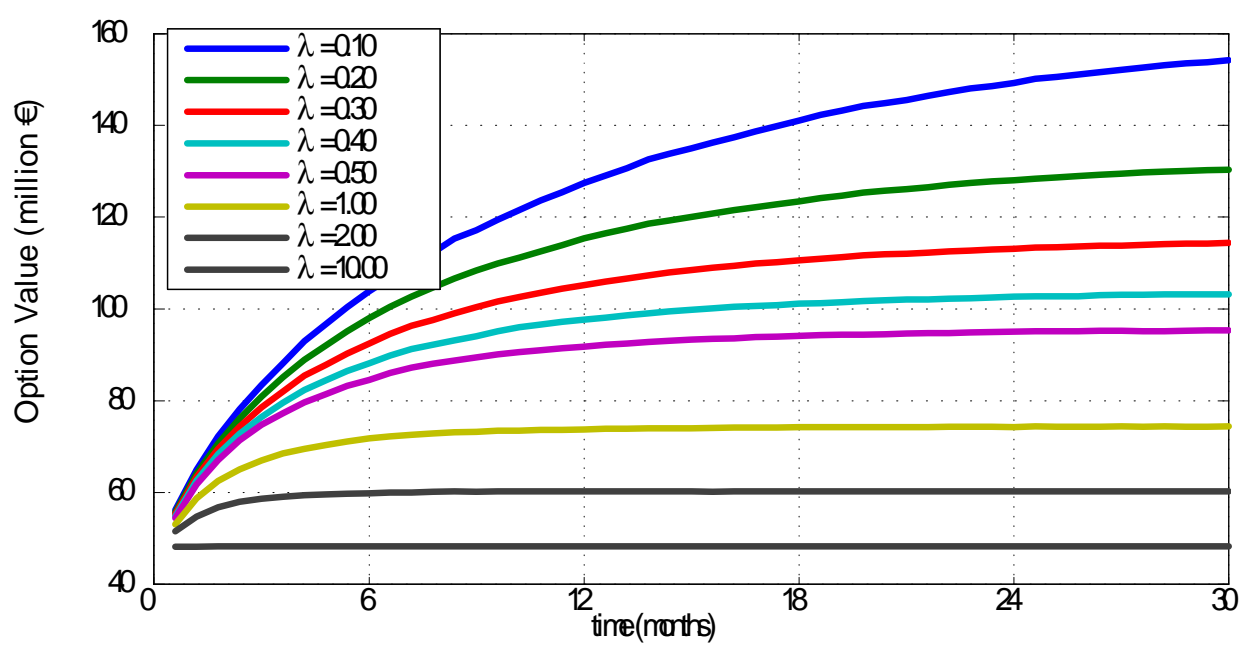

Figure 8: Value of the option to invest as a function of its maturity under several expiration probabilities.

calibrate a model for each price using actual market data. The first set consists of NYMEX Natural Gas futures contracts; the second one refers to the Spanish wholesale electricity market. Once we have described the basic features of our case study, the above operating plants are valued under the assumption of a finite useful life. Finally, Least Squares Monte Carlo Simulation is used to value several American-type options to invest in a natural gas power plant.

\section{A Valuation of annuities for an IGBM process}

\section{A.1 Annuity of natural gas}

In this model composed of equations (1) and (2), the expected values must satisfy the following differential equations:

$$
\begin{gathered}
E\left(d G_{t}\right)=k_{g}\left[E\left(L_{t}\right)-E\left(G_{t}\right)\right] d t, \\
E\left(d L_{t}\right)=\mu\left[L_{g}-E\left(L_{t}\right)\right] d t .
\end{gathered}
$$

From the second equation it is possible to get: $E\left(L_{t}\right)=L_{g}+\left(L_{0}-L_{g}\right) e^{-\mu t}$, and substituting in the first one results:

$$
E\left(d G_{t}\right)=k_{g}\left[L_{g}+\left(L_{0}-L_{g}\right) e^{-\mu t}-E\left(G_{t}\right)\right] d t .
$$

Using a factor of integration $e^{k_{g} t}$ and rearranging: 


$$
\begin{gathered}
e^{k_{g} t} E\left(d G_{t}\right)+k_{g} e^{k_{g} t} E\left(G_{t}\right) d t=\left[k_{g} L_{g} e^{k_{g} t}+k_{g}\left(L_{0}-L_{g}\right) e^{-\left(\mu-k_{g}\right) t}\right] d t, \\
e^{k_{g} t} E\left(G_{t}\right)=L_{g} e^{k_{g} t}-\frac{k_{g}\left(L_{0}-L_{g}\right)}{\mu-k_{g}} e^{-\left(\mu-k_{g}\right) t}+c .
\end{gathered}
$$

For $t=0$ then $E\left(G_{t}\right)=G_{0}$.

$$
c=G_{0}-L_{g}+\frac{k_{g}\left(L_{0}-L_{g}\right)}{\mu-k_{g}} .
$$

Solving for the expected value:

$$
E\left(G_{t}\right)=L_{g}-\frac{k_{g}\left(L_{0}-L_{g}\right)}{\mu-k_{g}} e^{-\mu t}+\left[G_{0}-L_{g}+\frac{k_{g}\left(L_{0}-L_{g}\right)}{\mu-k_{g}}\right] e^{-k_{g} t}
$$

For the particular case in which equation (2) reduces to a GBM type, the solution of Pilipovic [19] results.

Nonetheless, the last equation does not allow to compute the value of an anuity. It is necessary to use the risk-neutral version of the model composed by equations (8) and (9). Following the same steps we obtain:

$$
\begin{aligned}
& E\left(\hat{G}_{t}\right)=\frac{\mu k_{g} L_{g}}{\left(\mu+\lambda_{l} \xi\right)\left(k_{g}+\lambda_{g} \sigma_{g}\right)}\left(1-e^{-\left(k_{g}+\lambda_{g} \sigma_{g}\right) t}\right)+G_{0} e^{-^{\left(k_{g}+\lambda_{g} \sigma_{g}\right) t}}+ \\
& +\left[\frac{\mu k_{g} L_{g}}{\left(\mu+\lambda_{l} \xi\right)\left(\mu+\lambda_{l} \xi-k_{g}-\lambda_{g} \sigma_{g}\right)}-\frac{k_{g} L_{0}}{\left(\mu+\lambda_{l} \xi-k_{g}-\lambda_{g} \sigma_{g}\right)}\right] . \\
& \quad \cdot\left(e^{-\left(\mu+\lambda_{l} \xi\right) t}-e^{-\left(k_{g}+\lambda_{g} \sigma_{g}\right) t}\right)
\end{aligned}
$$

When $\lambda_{g}=\lambda_{l}=0$, we have equation (57).

The value of an annuity between time $\tau_{1}$ and time $\tau_{2}$ is determined by the following equation:

$$
V_{\tau_{1}, \tau_{2}}=\int_{\tau_{1}}^{\tau_{2}} E\left(\hat{G}_{t}\right) e^{-r t} d t
$$

The resulting value for the annuity is:

$$
\begin{gathered}
V_{\tau_{1}, \tau_{2}}=\frac{\mu k_{g} L_{g}}{r\left(\mu+\lambda_{l} \xi\right)\left(k_{g}+\lambda_{g} \sigma_{g}\right)}\left(e^{-r \tau_{1}}-e^{-r \tau_{2}}\right)+ \\
+\frac{\mu k_{g} L_{g}}{\left(\mu+\lambda_{l} \xi\right)\left(k_{g}+\lambda_{g} \sigma_{g}\right)\left(k_{g}+\lambda_{g} \sigma_{g}+r\right)}\left(e^{-\left(k_{g}+\lambda_{g} \sigma_{g}+r\right) \tau_{2}}-e^{-\left(k_{g}+\lambda_{g} \sigma_{g}+r\right) \tau_{1}}\right)+
\end{gathered}
$$




$$
\begin{gathered}
+\frac{k_{g} L_{0}}{\left(\mu+\lambda_{l} \xi-k_{g}-\lambda_{g} \sigma_{g}\right)\left(\mu+r+\lambda_{l} \xi\right)}\left(e^{-\left(\mu+\lambda_{l} \xi+r\right) \tau_{2}}-e^{-\left(\mu+\lambda_{l} \xi+r\right) \tau_{1}}\right)+ \\
+\frac{k_{g} L_{0}}{\left(\mu+\lambda_{l} \xi-k_{g}-\lambda_{g} \sigma_{g}\right)\left(k_{g}+r+\lambda_{g} \sigma\right)}\left(e^{-\left(k_{g}+\lambda_{g} \sigma_{g}+r\right) \tau_{1}}-e^{-\left(k_{g}+\lambda_{g} \sigma_{g}+r\right) \tau_{2}}\right)+ \\
+\frac{\mu k_{g} L_{g}}{\left(\mu+\lambda_{l} \xi\right)\left(\mu+\lambda_{l} \xi-k_{g}-\lambda_{g} \sigma_{g}\right)\left(\mu+r+\lambda_{l} \xi\right)}\left(e^{-\left(\mu+\lambda_{l} \xi+r\right) \tau_{1}}-e^{-\left(\mu+\lambda_{l} \xi+r\right) \tau_{2}}\right)+ \\
+\frac{\mu k_{g} L_{g}}{\left(\mu+\lambda_{l} \xi\right)\left(\mu+\lambda_{l} \xi-k_{g}-\lambda_{g} \sigma_{g}\right)\left(k_{g}+r+\lambda_{g} \sigma_{g}\right)}\left(e^{-\left(k_{g}+\lambda_{g} \sigma_{g}+r\right) \tau_{2}}-e^{-\left(k_{g}+\lambda_{g} \sigma_{g}+r\right) \tau_{1}}\right) \\
+\frac{G_{0}}{k_{g}+r+\lambda_{g} \sigma_{g}}\left(e^{-\left(k_{g}+\lambda_{g} \sigma_{g}+r\right) \tau_{1}}-e^{-\left(k_{g}+\lambda_{g} \sigma_{g}+r\right) \tau_{2}}\right) .
\end{gathered}
$$

When equation (2) is of the GBM form with $L_{g}=0$ and $\mu=-\varphi$, the value of the annuity is:

$$
\begin{gathered}
V_{\tau_{1}, \tau_{2}}=\frac{k_{g} L_{0}}{\left(\varphi-\lambda_{l} \xi+k_{g}+\lambda_{g} \sigma_{g}\right)\left(\varphi-r-\lambda_{l} \xi\right)}\left(e^{\left(\varphi-\lambda_{l} \xi-r\right) \tau_{2}}-e^{\left(\varphi-\lambda_{l} \xi-r\right) \tau_{1}}\right)+ \\
+\frac{k_{g} L_{0}}{\left(\varphi-\lambda_{l} \xi+k_{g}+\lambda_{g} \sigma_{g}\right)\left(k_{g}+r+\lambda_{g} \sigma_{g}\right)}\left(e^{-\left(k_{g}+\lambda_{g} \sigma_{g}+r\right) \tau_{2}}-e^{-\left(k_{g}+\lambda_{g} \sigma_{g}+r\right) \tau_{1}}\right)+ \\
+\frac{G_{0}}{k_{g}+r+\lambda_{g} \sigma_{g}}\left(e^{-\left(k_{g}+\lambda_{g} \sigma_{g}+r\right) \tau_{1}}-e^{-\left(k_{g}+\lambda_{g} \sigma_{g}+r\right) \tau_{2}}\right)
\end{gathered}
$$

If, in addition, $\varphi=0$ and $\xi=0$, we get the value of an annuity between $\tau_{1} \mathrm{y}$ $\tau_{2}$ which follows an IGBM process:

$$
\begin{gathered}
V_{\tau_{1}, \tau_{2}}=\frac{k_{g} L_{0}}{r\left(k_{g}+\lambda_{g} \sigma_{g}\right)}\left(e^{-r \tau_{1}}-e^{-r \tau_{2}}\right)-\frac{k_{g} L_{0}}{\left(k_{g}+\lambda_{g} \sigma_{g}\right)\left(k_{g}+r+\lambda_{g} \sigma_{g}\right)} . \\
\cdot\left(e^{-\left(k_{g}+\lambda_{g} \sigma_{g}+r\right) \tau_{1}}-e^{-\left(k_{g}+\lambda_{g} \sigma_{g}+r\right) \tau_{2}}+\frac{G_{0}}{k_{g}+r+\lambda_{g} \sigma_{g}}\left(e^{-\left(k_{g}+\lambda_{g} \sigma_{g}+r\right) \tau_{1}}-e^{-\left(k_{g}+\lambda_{g} \sigma_{g}+r\right) \tau_{2}}\right) .\right.
\end{gathered}
$$

Finally if also $\tau_{1}=0$ then:

$$
\begin{gathered}
V_{0, \tau_{2}}=\frac{k_{g} L_{0}}{r\left(k_{g}+\lambda_{g} \sigma_{g}\right)}\left(1-e^{-r \tau_{2}}\right)-\frac{k_{g} L_{0}}{\left(k_{g}+\lambda_{g} \sigma_{g}\right)\left(k_{g}+r+\lambda_{g} \sigma_{g}\right)} . \\
\cdot\left(1-e^{-\left(k_{g}+\lambda_{g} \sigma_{g}+r\right) \tau_{2}}\right)+\frac{G_{0}}{k_{g}+r+\lambda_{g} \sigma_{g}}\left(1-e^{-\left(k_{g}+\lambda_{g} \sigma_{g}+r\right) \tau_{2}}\right) .
\end{gathered}
$$




\section{A.2 Annuity of electricity}

In this case, fiven the parameters adopted, it is easy to show that the value of the annuity is:

$$
V_{\tau_{1}, \tau_{2}}=\frac{L_{e}}{r}\left(e^{-r \tau_{1}}-e^{-r \tau_{2}}\right)+\left(\frac{E_{0}}{k_{e}+r}-\frac{L_{e}}{k_{e}+r}\right)\left(e^{-\left(k_{e}+r\right) \tau_{1}}-e^{-\left(k_{e}+r\right) \tau_{2}}\right) .
$$

The first term in the right-hand side accounts for the equilibrium price, whereas the second one adds the spread between current price and the equilibrium price. 


\section{References}

[1] M.P. Baker, E.S. Mayfield and J.E. Parsons: "Alternative models of uncertain commodity prices for use with modern asset pricing methods". Energy Journal 19(1): 115-148, 1998.

[2] P. Bjerksund and S. Ekern: "Managing investment opportunities under price uncertainty: From "last chance" to "wait and see" strategies". Financial Management 19(3): 65-83, 1990.

[3] S. Bhattacharya: "Project valuation with mean-reverting cash flow streams". Journal of Finance XXXIII(5): 1317-1331, 1978.

[4] M.J. Brennan and E.S. Schwarz: "Evaluating natural resource investments". Journal of Business 58(2): 135-157, 1985.

[5] M.J. Brennan and L. Trigeorgis: Project flexibility, agency, and competition. Oxford University Press, 2000.

[6] G. Cortazar, M. Gravet and J. Urzua: "The valuation of multidimensional American real options using computer-based simulation". The 9th Annual Real Options Conference, 2005.

[7] G. Cortazar and E.S. Schwartz: "Monte Carlo evaluation model of an undeveloped oil field". Journal of Energy Finance \& Development 3(1): 73-84, 1998.

[8] G. Cortazar and E.S. Schwartz: "Implementing a stochastic model for oil futures prices". Energy Economics 25: 215-238, 2003.

[9] A. K. Dixit and R. S. Pindyck: Investment under uncertainty. Princeton University Press, 1994.

[10] ELCOGAS: Integrated gasification combined cycle technolgy: IGCC. Its actual application in Spain. 2003.

[11] R. Elliott, G. Sick and M. Stein: "Price interactions of baseload changes and electricity demand shocks". In E.I. Ronn(ed): Real options and energy management. Risk Books, 2002.

[12] M. Insley: "A real option approach to the valuation of a forestry investment". Journal of Environmental Economics and Management 44: 471-492, 2002.

[13] D.G. Laughton and H.D. Jacoby: "Reversion, timing options and long-term decision making". Financial Management 22(3): 225-240, 1993.

[14] D.G. Laughton and H.D. Jacoby: "The effects of reversion on commodity projects of different length". In L. Trigeorgis (ed.): Real options in capital investment. Praeger, 1995. 
[15] F.A. Longstaff and E.S. Schwartz. "Valuing American options by simulation: A simple least squares approach". Review of Financial Studies 14 (1): 113-147, 2001.

[16] D. Lund and B. Oksendal: Stochastic models and option values. NorthHolland, 1991.

[17] S. Majd and R.S. Pindyck :" Time to build, option value, and investment decisions". Journal of Financial Economics 18: 7-27, 1987.

[18] J. Paddock, D. Siegel and J. Smith: "Option valuation of claims on physical assets: The case of offshore petroleum leases". Quarterly Journal of Economics 103(3): 479-508, 1988.

[19] D. Pilipovic: Energy risk. McGraw-Hill, 1998.

[20] G. F. Robel. Real options and mean-reverting prices. The 5th Annual Real Options Conference, 2001.

[21] E.I. Ronn: Real options and energy management. Risk Books, 2002.

[22] S. Sarkar: "The effect of mean reversion on investment under uncertainty". Journal of Economic Dynamics and Control 28: 377-396, 2003.

[23] E. S. Schwartz: "The stochastic behavior of commodity prices: Implications for valuation and hedging". Journal of Finance 52(3): 923-973, 1997.

[24] E. S. Schwartz and J.E. Smith: "Short-term variations and long-term dynamics in commodity prices". Management Science 46(7): 893-911, 2000.

[25] E. S. Schwartz and L. Trigeorgis (eds): Real options and investment under uncertainty. The MIT Press, 2001.

[26] G. Sick: "Real options". In R. Jarrow et al. (eds): Handbooks in operations research and management science, vol 9: 631-691. Elsevier Science 1995.

[27] L. Trigeorgis: Real options - Managerial flexibility and strategy in resource allocation. The MIT Press, 1996.

[28] J. Watson: "Selection environments, flexibility and success of gas turbine". Research Policy, 33: 1065-1080, 2004.

[29] J.G. Weir: "Valuation of petroleum leases as real options". The 9th Annual Real Options Conference, 2005. 